\title{
A Relíquia do SANTO LENHO EM PoRTugal: NARRATIVAS DE MILAGRES
}

\author{
The Relic of the Holy Cross in PoRtugal: \\ NARRATIVES OF MIRACLES
}

\author{
Renata Cristina de Sousa Nascimento \\ renatacristinanasc@gmail.com
}

RESUMO: A relíquia do Lignum Crucis, cultuada como sendo parte da verdadeira cruz em que Cristo teria sido martirizado, insere-se no imaginário construído ao redor dos mistérios da paixão. Em Portugal, a ordem militar de São João de Jerusalém ou do Hospital, tornou-se a guardiã deste fragmento do Santo Lenho que se preserva na Igreja de Vera Cruz de Marmelar. Este objeto esteve presente em momentos cruciais da história da monarquia portuguesa, especialmente durante a Idade Média.

PALAVRAS-CHAVE: Relíquias; imaginário; poder simbólico.

ABSTRACT: A relic of the Lignum Crucis, worshiped as a part of the true cross on which Christ would have been martyred, is part of the imaginary built around the mysteries of passion. In Portugal, the Military Order of St. John of Jerusalem or the Hospital, became the guardian of this fragment of the Holy Cross which is preserved in the Vera Cruz Marmelar's church. This object was present at crucial moments in the history of Portuguese monarchy, especially during the Middle Ages.

KEYWORDS: Relic; imaginary; symbolic power.

\footnotetext{
" Doutora em História pela Universidade Federal do Paraná (UFPR) Participante do NEMED (Núcleo de Estudos Mediterrânicos- UFPR) Professora da Universidade Federal de Goiás (UFG), da Universidade Estadual de Goiás (UEG) e da Pontifícia Universidade Católica de Goiás (Mestrado em História).
} 
INTRODUÇÃO

Segundo a tradição a relíquia do Santo Lenho chegou a Portugal em meados do século XIII, trazida da Palestina. A existência e o culto às sagradas relíquias fazem parte da espiritualidade cristã e revelam o simbolismo oriundo destes objetos considerados sobrenaturais e capazes de mediar o contato entre o crente e Deus. O objetivo deste texto é analisar algumas narrativas de milagres relacionados à presença da Vera Cruz de Marmelar em momentos importantes da história portuguesa durante a Idade Média. Este objeto, santificado pela igreja e pela devoção popular, representaria a presença de Cristo, garantindo a vitória dos reis cristãos sobre os inimigos e, em outros momentos, o bom êxito da monarquia portuguesa frente às adversidades.

Para tanto dividimos o texto em três partes: As relíquias da paixão e a materialidade do sagrado; o Mosteiro de Marmelar e o Fragmento do Santo Lenho e, por último, narrativas e milagres atribuídos a relíquia do Santo Lenho em Portugal.

\section{Relíquias da PaixÃo: A MATERIALIdAde do SAGRADO}

A veneração às santas relíquias faz parte do imaginário cristão desde seus primórdios, embora sua promoção tenha sido gradativa e muitas vezes controversa. Elas cumprem a função de traduzir o invisível no visível. As relíquias são realidades materiais que têm por objetivo aproximar o homem do sagrado, cumprindo um papel cultual e espiritual, sendo fundamentais para o entendimento das práticas, dos rituais e das crenças cristãs. Os corpos dos mártires tornaram-se inicialmente objetos de veneração por parte dos cristãos ainda durante o período das perseguições. Dentre o mosaico de representações do sagrado transcendente as mais importantes são, sem dúvida, as que lembram a morte e a paixão de Cristo. Estas se tornaram as mais veneradas e numerosas da cristandade e sempre atraíram um enorme número de adoradores. 
Atribuiu-se a Helena, mãe do imperador Constantino (272337) a redescoberta dos lugares da paixão, que no ano de 326 teria peregrinado à terra santa e localizado o local da crucificação e o sepulcro de Jesus. O imperador endossou sua descoberta, lá construindo uma igreja, que, apesar de todas as vicissitudes, permaneceu como o principal santuário da cristandade, a Igreja do Santo Sepulcro ${ }^{1}$.

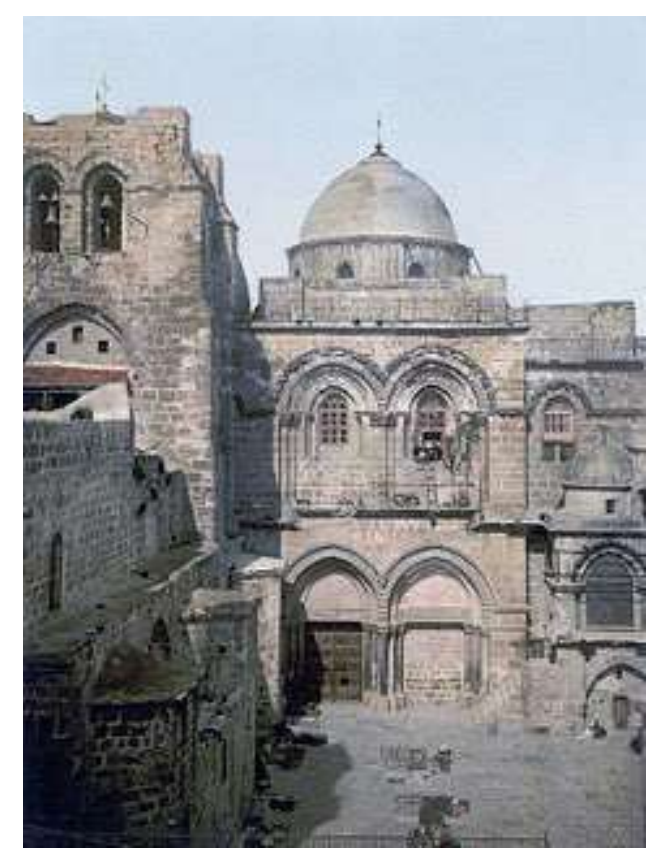

Igreja do Santo Sepulcro em Jerusalém www.paroquiasantosepulcro.org.br

Também o início da construção da primitiva Basílica da Natividade em Belém deve-se à sua intervenção. Para Jean- Claude Schmitt (2007, p. 282) "a madeira da cruz é mesmo a relíquia crística por excelência, desde os primeiros séculos do cristianismo". Estas são abundantes de um extremo ao outro da cristandade. Já desde o século IV vários fragmentos considerados oriundos da cruz de Cristo estavam espalhados pelas regiões cristãs. Outro objeto sacro ligado à passagem do Encarnado sobre a terra é 
o Santo Sudário, sendo o mais conhecido o da catedral de Turim, no norte da Itália. O Sudário é tido supostamente como o manto de linho que teria sido utilizado em torno de Jesus Cristo após a sua crucificação. Não é objetivo deste texto discutir a autenticidade das relíquias de Cristo e sim sua importância simbólica no seio da cristandade.

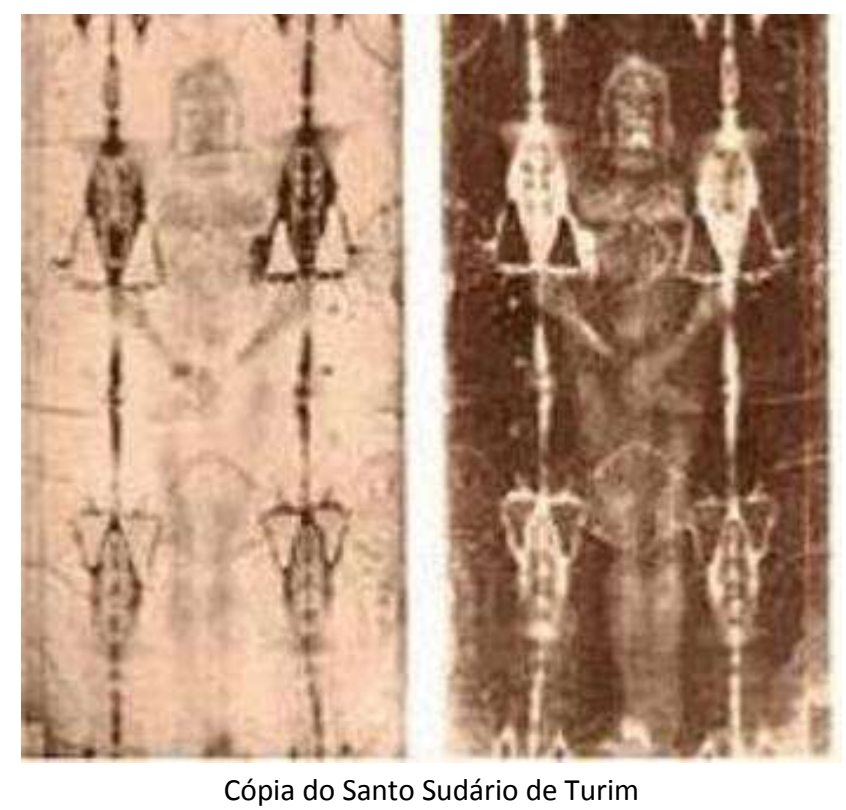

Outros símbolos relacionados à paixão, e que também foram objetos de culto, são a coroa de espinhos, os pregos da cruz de Cristo, o feno da manjedoura, o sangue sagrado, e a mesa da santa ceia. Os fiéis buscavam santificar suas vidas quando entravam em contato com estas relíquias. Muitos queriam resolver problemas cotidianos como doenças, fome e perdão de pecados. Necessidades físicas e morais que poderiam ser supridas em contato direto com a sacralidade.

...é fácil compreender as razões de sua proliferação na medida em que as pretensas relíquias corporais se inscreviam numa lógica 
própria do cristianismo, que a Encarnação enraizou na história da humanidade, o corpo. A Encarnação não é apenas um dogma particular, mas revela uma forma de pensamento que imprimiu sua marca em todas as representações e práticas características do cristianismo, quer se tratasse da noção cristã do sacrifício, das relíquias ou das imagens. (SCHMITT, 2007, p. 282)

A cidade de Bizâncio era muito conhecida no ocidente exatamente por possuir uma invejável coleção de relíquias. Dentro desta lógica encontram-se também as peregrinações. As principais cidades medievais que recebiam peregrinos eram Roma, Santiago de Compostela (intensificada a partir do século VIII) e especialmente Jerusalém. Ali na Palestina os crentes poderiam rememorar o cenário da vida de Cristo. ${ }^{2} \mathrm{~A}$ sensação do contato místico, aliada à necessidade da materialidade da fé, impulsionava o desejo de peregrinar, e é a partir desta prática que se pode enquadrar o aprimoramento das condições de peregrinação que exerceram um enorme efeito sobre a religiosidade ocidental. No entanto, a viagem ainda era longa e árdua ao palmeiro, ${ }^{3}$ os desconfortos e "as despesas de sua jornada iriam servi-lhe como punição, enquanto o cumprimento da tarefa e a atmosfera emocional de sua meta provocariam nele uma sensação de purificação e força espiritual. Ao voltar acreditava-se um homem melhor" (RUNCIMAN, 2003, p. 51). O papel essencial assumido pelo contato direto com imagens e objetos ao qual eram atribuídos poderes miraculosos, incentivavam o ato de peregrinar, pois estes ofereciam um meio de comunicação com o mundo espiritual, garantindo a vitalidade do cristianismo.

\section{O Mosteiro do Marmelar e o Fragmento do Santo Lenho}

O fracionamento do que a tradição afirmava serem pedaços da "verdadeira cruz", levado a extremos, garantiu sua redistribuição, ocupando o culto das relíquias do Santo Lenho lugar de relevo também na Península Ibérica. Estes fragmentos serviram como motivadores de 
devoção, adoração e de peregrinações. Como principal marca do sacrifício e padecimento de Cristo, a cruz é o elemento simbólico por excelência do cristianismo medieval. Os locais de adoração aos fragmentos do Lignum Crucis se multiplicaram no ocidente, sendo intensificado durante a realização das cruzadas (séculos XI- XIII). Em Portugal a ordem militar de São João de Jerusalém ou do Hospital tornou-se a guardiã da relíquia do Santo Lenho que se preserva na Igreja de Vera Cruz de Marmelar, freguesia do município de Portel, sendo o rei D. Afonso III o promotor da formação do senhorio de Portel em 1257.

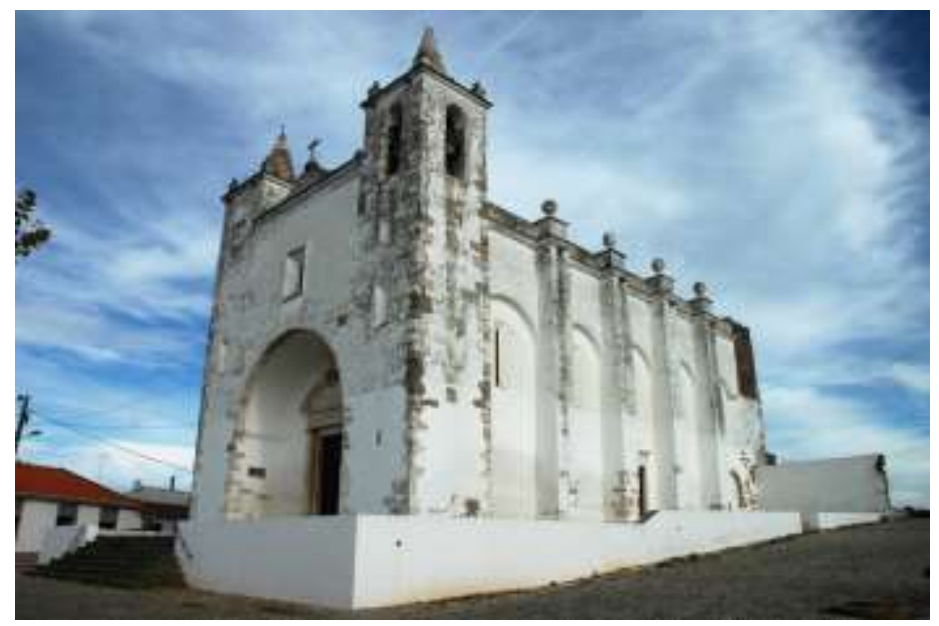

Igreja de Vera Cruz de Marmelar- Portel (PT)

A Ordem de São João é originária de um grupo de mercadores de Amalfí que fundaram, em meados do século XI, um hospital próximo ao Santo Sepulcro em Jerusalém, pois com a tomada desta cidade em 1099 a necessidade de proteção da terra santa e dos peregrinos fez proliferar a criação das ordens militares. Estas representam uma novidade, no palco da espiritualidade, obtendo o Hospital em 1113 a aprovação papal. 
A existência em Jerusalém de um hospital voltado para o alojamento e o cuidado dos peregrinos, assim como daqueles entre eles que estavam cansados ou doentes fortaleceu o elo entre a obra de assistência e de caridade e a Terra Santa. Ao fazer, em 1113, do Hospital de Jerusalém um estabelecimento central da ordem, Pascoal II estimulava a filiação dos hospitalários do Ocidente a ele, sobretudo daqueles que estavam ligados à peregrinação na Terra Santa ou em outro lugar: aquelas da via Francígena que levava a Roma e mais além para os portos da Itália do Sul: aqueles da rota do Ródano, na foz do qual Saint- Gilles foi o principal centro do Hospital na França. A militarização do Hospital de Jerusalém não obliterou a vocação caritativa primitiva, mas a fortaleceu. (DEMURGER, A, 2002, p. 129130)

Da assistência direta aos pobres e peregrinos a Ordem passou a ter gradativamente função militar, relacionada com a defesa do litoral sírio- palestino no oriente e depois na Europa, especialmente em função da reconquista. Na Península Ibérica, as ordens militares também tiveram uma significativa ação durante todo o período medieval. Inicialmente obtiveram territórios na Galiza, estendendo-se posteriormente ao norte e ao sul do que é hoje Portugal. A Comenda da Vera Cruz de Marmelar, tornou-se neste cenário de proteção de fronteiras pós- reconquista e fortalecimento do poder real, veículo importante da presença hospitalária na região. ${ }^{4}$ Segundo a tradição esta comenda teria início no século XIII. Para Paula Pinto Costa (2000) a esta comenda esteve associada um simbolismo muito grande, devido ao fato de ter sido escolhida para depósito de um fragmento do Santo Lenho, que marcaria a sua evolução histórica futura e alteraria o estatuto do mosteiro.

A edificação da estrutura inicial do futuro Mosteiro de São Pedro de Vera Cruz remonta ao período visigótico, sendo hoje aceite a existência, no mesmo lugar, de um estabelecimento monástico desde o século VII. Este foi refundado pela Ordem do Hospital em meados do século XIII, como já afirmamos.

A carga simbólica que a Igreja de Vera Cruz encerra é oriunda da presença da relíquia do Santo Lenho, sendo desde sua chegada objeto 
de grande devoção. "Segundo a tradição, a famosa relíquia do Santo Lenho de Marmelar terá sido trazida da Palestina por D. Afonso Pires de Farinha, quando da realização de uma viagem à Terra Santa". (PAGARÁ, 2006).

Segunda notícia do santíssimo lenho do Agiologio Luzitano, composto pello llustre Jorge Cardozo no Tomo 3 o folha 55 e diz a noticia depois de haver tratado o author de outras couzas - as palavras seguintes: (...) esta Famoza relliquia trouxe de Hierusalem Fr. Affonso Pires Farinha Prior do Hospital, o qual edificou este mosteiro [de Marmelar] à instância do illustre D. João de Aboim (...). He certo, segundo a tradição e voz constante, que vinha esta relliquia a Sée de Évora deregida e chegando ao lugar da Fonte Santa, nunca a mula que a trazia quis passar adeante athe que lhe foi tirada a sagrada carga e para que não service em profanos uzos, estalou de repente, com admiração de todos, que ali se acharão; e para ficar mais famoso o prodígio brotou a terra hum canal de agoa que houje persevera com o titolo da Fonte Santa. E conforme a mesma tradição consta que o Arrieiro metendo na terra a vara com que picava a mula, em continente se vio hum fermozo pinheiro de que ainda há memorias, e de que levando os romeiros feito em cruzes obrava por ellas o Ceo grandes maravilhas; tudo isto consta da tradição à qual nada acrescento, e ainda houje por maravilha se concerva o pé do dito pinheiro tão fresco e verde, que he admiração de todos ...(Patalim, $1730)^{5}$

Inicialmente o fragmento da cruz teria sido endereçado à Sé de Évora, mas por circunstâncias miraculosas, como sugere o documento, o mesmo teria, por vontade divina, permanecido na aldeia do Marmelar. Posteriormente teria sido dividido entre Vera Cruz do Marmelar e Évora.

Fator determinante de atração de peregrinos de várias regiões, sua importância vai além das questões religiosas, influenciando diretamente na economia do lugar. O culto se confunde com a própria história da região. A parte do fragmento da cruz que teria sido entregue à Sé de Évora após a Batalha do Salado de 1340 mantém (desde 1933) apenas valor patrimonial. A que ficou em Marmelar continua ainda sendo fator de interesse religioso por parte dos fiéis. Depositada em um cofre relicário de prata, manda do fazer por Nuno Álvares Pereira, este objeto também foi 
usado em cerimônias de exorcismo. Esta prática ajudou a credibilizar o signo miraculoso da relíquia.

Outro aspecto importante que merece ser ressaltado é a relação entre arte e espiritualidade, pois a arte medieval acolhe a alegoria do sagrado. "Igrejas são livros simbólicos e abertos do catecismo cristão" (GOMES, 2013). A cruz relicário existente em Marmelar compõe a áurea de sacralidade presente no espaço da capela do Mosteiro.

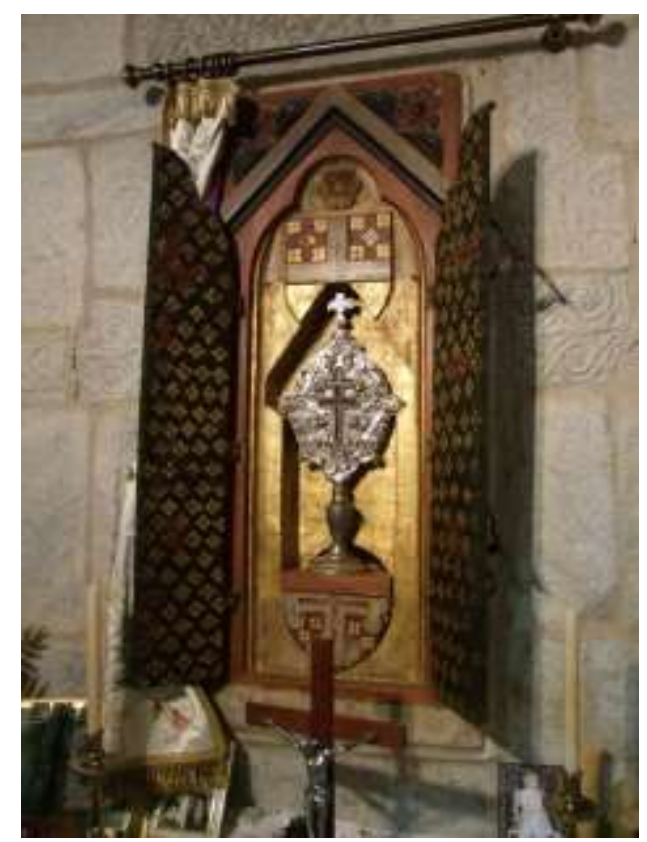

Capela do Santo Lenho em Marmelar. Cofre- relicário onde se venera a relíquia do Lignum crucis.

3- Narrativas e Milagres Atribuídos à Relíquia do Santo Lenho em Portugal

A fonte cristã por excelência que narra a intervenção divina e miraculosa na vida de homens e mulheres é a Bíblia Sagrada. Desde o Antigo Testamento encontram-se vários textos em que o milagre acontece por interseção humana junto à divindade. $O$ modelo crístico é sem dúvida o 
mais habitual, sendo também presentes nas narrativas bíblicas a realização de milagres pelos fundadores da Igreja, Pedro e Paulo. No livro de Atos dos Apóstolos encontram-se várias passagens que serviriam, posteriormente, para legitimar a presença de milagres na vida do crente, sendo algo muito almejado pelos fiéis. "E Deus pelas mãos de Paulo fazia maravilhas extraordinárias. De sorte que até os lenços e aventais se levavam de seu corpo aos enfermos, e as enfermidades fugiam deles, e os espíritos malignos saíam" (Atos, 19: 11-12). Os sinais visíveis da presença divina fizeram parte também dos escritos dos pais fundadores. No capítulo XII do Livro X da Cidade de Deus Santo Agostinho afirma:

Quanto aos milagres, sejam quais forem, operados pelos anjos ou por qualquer outro modo, se se destinam a glorificar o culto da religião do verdadeiro Deus, princípio único da vida bem- aventurada, devem ser atribuídos aos espíritos que nos amam com verdadeira caridade, é preciso acreditar ser o próprio Deus quem neles e por eles opera. Não demos atenção, por conseguinte, a homens que ao Deus invisível recusam a faculdade de operar milagres visíveis, pois, segundo eles mesmos, é o autor do mundo, cuja visibilidade não poderiam negar. Nada de maravilhoso acontece neste mundo que não esteja abaixo da maravilha do mundo, obra de Deus; mas, como o próprio artífice, o segredo de sua operação é incompreensível ao homem. Embora o permanente milagre da natureza visível tenha, a nossos olhos acostumados a vê-lo, perdido algo do valor, a inteligência que seriamente o considera acha-o superior aos milagres mais extraordinários e mais raros. (Agostinho. S. 2009, p. 385)

O Homem seria o instrumento de Deus na realização de prodígios que também poderiam ocorrer através de algum objeto que tivesse tido contato com portadores desta santidade. Uma partícula do corpo (muitas vezes incorruptível) ou da veste de um santo também compunham este cenário de sacralidade. Os milagres desempenham um relevante papel na vida espiritual e, como afirma Vauchez (1995), eles constituem um dos mais importantes meios de comunicação entre este mundo e o além, por isso os cristãos da Idade Média viviam permanentemente em busca de milagres, e dispostos a identificá-los em qualquer fenômeno extraordinário. A atitude reservada de alguns teólogos 
e canonistas diante da realidade miraculosa, e o esforço das autoridades eclesiásticas em comprovar a veracidade dos milagres não conseguiu diminuir o poder que estes exerciam sobre a mente dos fiéis.

Neste contexto é que vamos procurar analisar duas narrativas em que a "Vera Cruz" se faz presente. Antes, no entanto, é preciso destacar que o caris devocional relacionado à relíquia esteve sempre presente na corte durante os séculos XIV e XV. D. Dinis (1261-1325) a teria tomado por empréstimo especialmente para sua particular veneração. Em seu testamento deixou ordem expressa para que a mesma fosse devolvida para o Mosteiro de Marmelar; “(...) e mando que tornem logo ao Marmelar a Cruz de Ligno Domini que ende eu mandei filhar emprestada, caa nó filhei eu se no por devaçam, que em ella avia, e com entençom de a fazer tornar hu ante ssia. [Testamento do Rei D. Dinis, 1322] ${ }^{6}$

Entre os relatos sobre a sacralidade da Vera Cruz o mais conhecido está ligado à vitória dos cristãos (castelhanos e portugueses) sobre os muçulmanos na Batalha do Salado de 1340. A presença do Santo Lenho garantiu a vitória sobre os infiéis, sublinhando seu caráter extraordinário e sobre- humano. As refundições do Livro de Linhagens do Conde D. Pedro deram ao Prior do Hospital Frei Álvaro Gonçalves Pereira lugar de destaque, sendo portador da relíquia e instrumento da ação divina. A importância dada pela historiografia à Memória do Salado enfatiza a construção de imagens sobre a vitória cristã que valorizam a ação do Prior do Crato no confronto.

Para Fátima Fernandes $(2011,80)$ "a interpolação realizada no Livro de Linhagens do Conde D. Pedro seria um projeto laudatório da linhagem dos Pereira através da consagração da figura do Prior". Além do Livro de Linhagens a Crónica Geral de Espanha de 1344 e a Crónica de D. Afonso IV nos oferecem elementos sobre a Batalha. Dentre estas escolhemos analisar o texto da Crónica de $D$. Afonso IV, de autoria de Ruy de Pina. Em seu capítulo LIX cujo tema é "Como a batalha do Salado foy cometida, \& os mouros foram nella vencidos" Pina nos oferece uma narrativa sobre o efeito da presença do Santo Lenho; 
E a este próprio tempo elRey Dom Affonso de Portugal compria idade de sincoenta annos, o qual hum pouco antes de romper com suas batalhas nas hazes dos Mouros, fez aos seus Portuguezes huma breve falla ...\& loguo elRey mandou a Dom Aluaro Gil de Pereira, Prior do Crato, que antes de encontrarem mostrasse o Lenho da vera Cruz, que levava do Marmelar, o qual trouxe loguo hum Clerigo reuestido, posto em huma hastea aleuantada como bandeyra, \& o Prior disse a el Rey. (Senhor tende Fee, \& devaçam neste final vistoriszo da vera Cruz, porque na virtude delle hoje vecereis seus inimigos). \& depois que a Cruz com muyta devaçam foy de elRey, \& de todos os que a viram adorada, \& pedido a Deos, que pela virtude, \& grandes merecimentos della os ajudasse tomarão diante desy a mesma Cruz por guia, \& seguio loguo apoz Ella a bandeira Real de Portugal, que levava o ditto Gonçallo Correa de Azevedo...o qual devotamente hia cantando o Psalmo (PINA, 1936, p. 168).

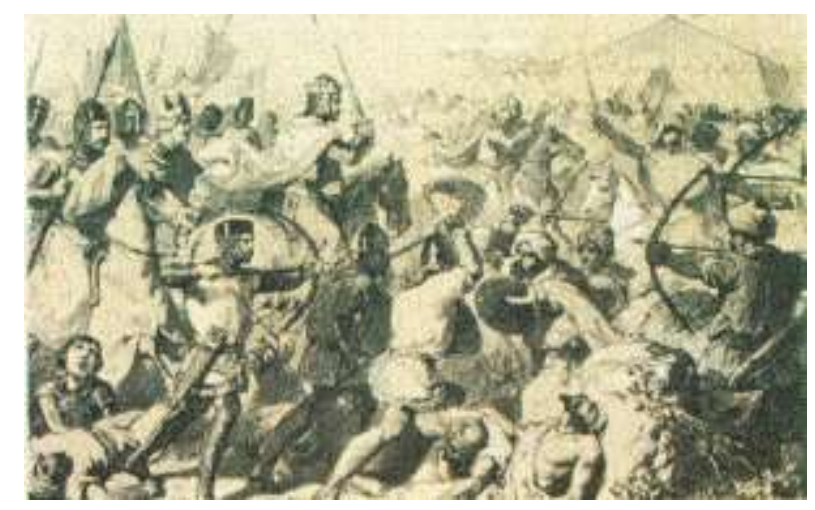

Batalha do Salado. Arquivo Histórico Militar. Lisboa

A intencionalidade discursiva, presente no texto da crônica, nos conta sobre a intervenção do maravilhoso, através da fé no Santo Lenho, cumprindo assim as palavras proféticas de Dom Álvaro. É a própria presença de Cristo (sentida no fulgor da luta), emanada através da relíquia que propiciou a vitória sobre as hostes infiéis. É preciso entender este episódio como parte intrínseca ao imaginário medieval. A presença deste por si só possuía valor santificante. A narrativa do Salado está recheada de 
passagens que confirmam estas manifestações da sacralidade, fazendo com que o texto seja dotado de uma ambiguidade, um duplo sentido (real/imaginário) que, no entanto não invalidam seu sentido realístico. (COSTA, 2002)

Outra narrativa que oferece elementos da ação mediadora da relíquia do Marmelar é o Trautado da Vida e Feitos do Muitto Vertuoso Sor Iffante D. Fernando, mais conhecida como Crônica do Infante Santo, composto entre 1451 e 1460 por Frei João Álvares (NASCIMENTO, 2012) Já no início do discurso são narradas às dificuldades enfrentadas pela Rainha Filipa de Lencastre (1359-1415), esposa do rei D. João I, que não gostaria de perder seu filho ainda em gestação. Tendo partido em peregrinação a Igreja de Vera Cruz de Marmelar teve bom parto: "e mando à fanta vera Cruz do Marmelar pelo preciofo lenho da Cruz. Que ahi eftá. E foy Deos fervido, que depois de alguns dias tiveffe a Rainha bom e feguro parto; e pario a effe Infante no anno de Chrifto de 1402, dia de São Miguel." (ÁLVARES: 37). A cura propiciada pelo toque revela a carga emocional devotada à relíquia. $\mathrm{A}$ experiência mística produzida pela presença divinizada e concreta da cruz do Filho de Deus traz alento diante da adversidade. "O elemento afetivo torna-se preponderante na mística medieval". (VAUCHEZ, 1995, p. 197) Um ato de Deus, crível por seus adoradores e que os aproximava de seu criador, revelando o valor da experiência aliada à espiritualidade.

\section{NOTAS}

1 No século VII esta igreja foi destruída após a invasão dos persas, sendo reconstruída pelos bizantinos. Após a tomada de Jerusalém (1099) na primeira cruzada a Basílica foi novamente reconstruída.

${ }^{2}$ A primeira notícia da presença de peregrinos do ocidente peninsular nos Lugares Santos da Palestina é a de Etéria, que em 16 de dezembro de 383 visita o Monte Sinai.

${ }^{3}$ Em Portugal, nos últimos séculos da Idade Média, os peregrinos que regressavam de Jerusalém eram designados por palmeiros. Este epíteto era uma rememoração da tradição bíblica que afirma que os habitantes da Cidade Santa haviam saldado 
Jesus de Nazaré com uma palma, em sua entrada pela cidade montado em uma mula.

4 “Ao comendador cabia não só a responsabilidade de zelar pelo bom funcionamento das propriedades que lhe estavam confiadas, por inerência ao cargo, como também a obrigação de manter a correção da comunidade (membros da ordem e paroquianos) na sua vivência espiritual, garantindo o regular funcionamento dos ofícios e outros serviços religiosos". PAGARÁ. Ana \& outros. Igreja Vera Cruz de Marmelar. Portel: Página Editores, 2006. P 37

${ }^{5}$ Documento publicado em Igreja Vera Cruz de Marmelar, organizado por Ana Pagará et alii. 2006, p 51.

${ }^{6}$ Documento publicado em Igreja Vera Cruz de Marmelar, organizado por Ana Pagará et alii. 2006, p 53.

\section{REFERÊNCIAS BIBLIOGRÁFICAS}

AGOSTINHO, Santo. A Cidade de Deus. v. I. Petrópolis: Vozes, 2009.

ALVARES. Frei João. Chronica dos Feytos, Vida, e Morte do Infante Fanto D. Fernando, que Morreo em Fez. In: RAMOS, Jerônimo de. Lisboa: Oficina de Miguel Rodrigues, 1730.

CARVALHO. Rui G de. O Santo Lenho da Sé de Évora: arte, esplendor e devoção. Lisboa: Fundação Eugénio de Almeida, 2011.

COSTA, Paula Maria P. A Ordem Militar do Hospital em Portugal: dos finais da Idade Média à Modernidade. In: Militarium Ordinum Analecta. Fundação Eng. Antônio de Almeida, 3/4, 1999/2000.

; PIMENTA, Maria C. A Cruzada e os objetivos fundacionais das Ordens Religioso- Militares em Portugal. Separata da Revista Portuguesa de História, Tomo XL, Coimbra: Faculdade de Letras da Universidade de Coimbra, 2008/2009.

Leão, 2010

. A Presença dos Hospitalários em Portugal. Gavião: Ramiro

COSTA. Ricardo da. A mentalidade de cruzada em Portugal (séculos XIIXIV). In: Anos 90 - Revista do Programa de Pós- Graduação em História da UFRGS. N 16. Porto Alegre: 2001- 2002. p 143- 178. 
CROSSAN, John Dominic \& REED. Jonathan L. Em busca de Jesus: debaixo das pedras, atrás dos textos. SP: Paulinas, 2007.

DEMURGER. Alain. Os Cavaleiros de Cristo: Templários, Teutônicos, Hospitalários e outras Ordens Militares na Idade Média. RJ: Jorge Zahar, 2002.

FERNANDES, Fátima Regina. O Poder do relato na Idade Média Portuguesa: a Batalha do Salado de 1340. In: Revista Mosaico. n. 4. Goiânia: PUC-GO, 2011, p. 75- 91.

de Nuno Álvares Pereira. In: A guerra e a sociedade na idade média. VI Jornadas Luso- Espanholas de Estudos Medievais. v. I Alcobaça- Batalha, 2009. p 421- 446

FRANCO, Hilário Jr. Relíquia, metonímia do sagrado. In: Historiae, v. 1, n. 1, UFRG, 2010, p. 9-29.

GOMES, Saul A. Hagiografia, arte e cultura no Outono da Idade Média. 2013. (Artigo no prelo)

GUIMARAES, Marcella Lopes. Por São Jorge! Por São Tiago! Batalhas e narrativas ibéricas medievais. Curitiba: UFPR, 2013.

LE GOFF, J. Heróis e maravilhas da Idade Média. Rio de Janeiro: Vozes, 2009.

MARCHINI, Dirceu. A Ordem do Hospital no noroeste da Península Ibérica: doações e privilégios (séculos XII- XV). Dissertação de Mestrado. Porto: Faculdade de Letras da Universidade do Porto, 2010.

NASCIMENTO, Renata Cristina de. O Martírio do Infante Santo e a expansão portuguesa (século XV). In: Anais do XXVI Simpósio Nacional de História. SP: ANPUH, 2011, p. 106-116.

; MARCHINI. D. A Idade Média: entre a história e a historiografia. Goiânia: PUC- GO, 2012.

O Novo Testamento. Tradução de João Ferreira de Almeida. Filadélfia: CNP, 1994/1995. 
PAGARÁ. Ana et. al. Igreja Vera Cruz de Marmelar. Portel: Página Editores, 2006.

PINA, Rui de. Crónica de ELRei Dom Afonso o Quarto. Lisboa: Biblion, 1936.

RAMOS, Rafael C. Arquitectura fronteriza portuguesa: La Vera Cruz de Marmelar, un enclave de la Reconquista lusa. In: Laboratório de Arte 21. Sevilha, 2008-2009, p. 37-65.

RUNCIMAN, Steven. História das cruzadas: A Primeira Cruzada e a fundação do Reino de Jerusalém. v. 1. Rio de Janeiro: Imago, 2003.

SCHMITT. Jean- Claude. O corpo das imagens- Ensaios sobre cultura visual na Idade Média. Tradução de José Rivair Macedo. Bauru, SP: Edusc: 2007.

SOUSA, Bernardo Vasconcelos e. O Sangue, a Cruz e a Coroa - A memória do Salado em Portugal. In: Penélope: Fazer e Desfazer História. n. 2. Lisboa: 1989, p. 28- 44.

VAUCHEZ. André. A Espiritualidade da Idade Média Ocidental (séc. VIII- XIII). Lisboa: Estampa, 1995.

. Milagre. In: LE GOFF, J; SCHMITT, J-C. (org.) Dicionário

Temático do Ocidente Medieval. v. II. Bauru/SP: EDUSC, 2002, p. 197- 212. 